\title{
Critical thinking and creativity of MSMEs in improving business performance during the covid- 19 pandemic
}

\author{
Siti Mujanah ${ }^{a}$, I Dewa Ketut Raka Ardiana ${ }^{a}$, Riyadi Nugroho ${ }^{a}$, Candraningrat $^{\mathrm{b}}$, Achmad Yanu Alif \\ Fianto $^{\mathrm{b}}$ and Donny Arif ${ }^{\mathrm{c}}$
}

${ }^{a}$ Faculty of Economy and Business, Universitas 17 Agustus 1945 Surabaya, Surabaya 60118, Indonesia

${ }^{b}$ Fakultas Ekonomi dan Bisnis, Universitas Dinamika, Indonesia

'Cniversitas Maarif Hasyim Latif, Indonesia

A B S T R A C T

\begin{tabular}{l} 
Article history: \\
Received July 18, 2021 \\
Received in revised format \\
September 24, 2021 \\
Accepted October 302021 \\
Available online \\
October 312021 \\
\hline Keywords: \\
Critical Thinking \\
Creativity \\
Employee Performance \\
COVID-19
\end{tabular}

\begin{abstract}
The purpose of this descriptive-explanatory study is to examine the relationship between critical thinking and creativity and the performance of Micro, Small, and Medium-sized businesses (MSMEs) in Indonesia during the coronavirus disease 2019 (COVID-19) pandemic. In this study, a questionnaire instrument was used, which was given online using Online Survey Forms, to collect information from a sample of 108 business managers who were selected at random to participate. Using the SmartPLS software, an analysis was performed once the data had been collected. The results indicate a substantial impact on the performance of MSMEs in Indonesia was found to be associated with critical thinking and innovation, according to the findings.
\end{abstract}

\section{Introduction}

Businesses of all sizes, including Micro, Small, and Medium-sized Enterprises (MSMEs), play a critical and important part in the development of a country's economy (Amankwah-Amoah, Khan, \& Wood, 2021; Bouwman, Nikou, \& de Reuver, 2019; Paik, Kim, \& Park, 2017; Prasetyo \& Kistanti, 2020; Pu, Qamruzzaman, Mehta, Naqvi, \& Karim, 2021; Ramli, Firdaus, Arief, \& Setiawan, 2019; Tiago, Gil, Stemberger, \& Borges-Tiago, 2020). The critical role of MSMEs not only contribute significantly to economic growth and employment, but they also play an essential role in the distribution of development outcomes and benefits (Amankwah-Amoah et al., 2021; Bouwman et al., 2019). Aside from that, it has been shown that MSMEs are unaffected by the global economic crisis, which is a promising trend (Colovic, 2021; Fianto, 2018). MSMEs are also able to provide substantial contributions to the national economy under normal conditions; domestic consumption accounts for about 80 percent of Indonesia's Gross Domestic Product (GDP). MSMEs also can handle more than 96 percent of the total 170 million workers, according to the Bureau of Labor Statistics. As a result of the coronavirus disease 2019 (COVID-19) pandemic (Amankwah-Amoah et al., 2021), which has spread throughout the world, including Indonesia, and the number of afflicted people continues to increase, MSMEs in Indonesia have been forced to shut the business down (Mujanah et al., 2017; Ramli et al., 2019; Tiago et al., 2020). The COVID-19 outbreak, which was first detected in Indonesia in early March, has already spread across the nation, with the number of confirmed cases rapidly increasing. According to the Indonesian government, individuals should be encouraged to engage in a range of activities at home, such as working, learning, and praying, among others (Prasetyo \& Kistanti, 2020; Pu et al., 2021). Individuals' economic activity is unquestionably affected as a result of these circumstances (Paik et al., 2017; Prasanna et al., 2019). Stock market indexes

* Corresponding author

E-mail address: sitimujanah@untag-sby.ac.id (S. Mujanah)

(c) 2022 Growing Science Ltd. All rights reserved.

doi: $10.5267 /$ j.uscm.2021.10.014 
also have dropped significantly, the Rupiah has weakened, and businesses in the real estate sector are facing increasing problems (Bouwman et al., 2019; Colovic, 2021). Furthermore, proprietors who have experienced a slump in their businesses or who have been forced to close their doors will face increased challenges as a result of the COVID-19 (Amankwah-Amoah et al., 2021). Entrepreneurs are required to think critically and creatively in this environment in order to develop new businesses that can be run from home and are in great demand by a big number of consumers (Cerchione et al., 2016; Kumar \& Kalse, 2021; Rakshit et al., 2021). The ability of the marketing team to think critically is essential to the ability of the marketing team to develop and execute a successful marketing campaign (Adam \& Alarifi, 2021). It is essential for the marketing department of an organization to be able to collect and analyze demographic information about the company's target audience in order to identify the most effective methods of reaching customers when promoting the organization's products (Rakshit et al., 2021). As a consequence, developing critical thinking skills is very important in business operations in order to offer products and services successfully (Kumar \& Kalse, 2021; Paik et al., 2017). The ability to solve problems via critical thinking refers to the capability of systematically gathering information about the problem, developing new ideas that include different points of view, using logical information, and ensuring that everyone is involved in the process (Melnyk et al., 2021). Because it will allow a businessperson to find the best solution to the problem MSMEs is facing, while garnering the greatest degree of support from all parties concerned, critical thinking is very important for a businessperson to have. When it comes to the efficient use of time and resources, critical thinking will also help in the reduction of stress in the workplace, which is especially essential at this time, when businesses are coping with the challenges brought on by the COVID-19 pandemic epidemic (Amankwah-Amoah et al., 2021; Rakshit et al., 2021). Additionally, in order to effectively sell their products and generate profits in the current climate, companies must achieve a breakthrough in their operations (Pu et al., 2021). The growth of business managers' creativity is also very important, since when they have creativity on their side, their capacity to innovate, be more effective, and be more understandable is greatly improved (Bouwman et al., 2019; Viswanathan \& Telukdarie, 2021). Creative thinking is the process of combining several existing elements to create something entirely new, with the ultimate aim of upgrading the product to something that has never been seen before in the marketplace (Ramli et al., 2019). The ability to add value, create value, and discover business possibilities are all closely linked to the ability to think creatively (Desouza \& Awazu, 2006). It is the phrase "creative thinking" that is used to define the patterns that are needed to depict the condition of the future in which an entrepreneur will operate, as well as to give an image that cannot be produced just by looking at existing trends (Ramli et al., 2019). Furthermore, according to prior research, when it comes to identifying new business opportunities, creativity has a positive impact on corporate strategies. In order for MSMEs success to be achieved, increased product diversification in response to consumer demand is essential; additionally, developing an appropriate marketing strategy for offering products or services is essential so that they can sell their products during the COVID-19 pandemic, when customers are accustomed to making online purchases at this time, is essential (Adam \& Alarifi, 2021; Amankwah-Amoah et al., 2021; Kumar \& Kalse, 2021). As a result, creative thinking is needed in order to guarantee the long-term sustainability of MSMEs business operations throughout the COVID-19 pandemic (AmankwahAmoah et al., 2021).

Taking into account the theoretical and empirical perspectives discussed above, which indicate that someone who wishes to develop their business will tend to implement strategies to seek out business opportunities, this research was conducted in order to provide a contribution to MSME's on how to keep their businesses alive during the COVID-19 pandemic, whether critical and creative thinking is necessary in developing a business during the COVID-19 pandemic (Melnyk et al., 2021). However, most previous studies have focused on critical thinking skills in students, with only a handful of studies focusing on the critical thinking skills of entrepreneurs in dealing with the crisis of the COVID-19 pandemic, which resulted in a decrease in people's purchasing power and, as a result, had an adverse impact on the performance of MSMEs in Indonesia. Because of this, the aim of this research is to investigate the relationship between critical thinking and creativity and the performance of MSMEs at the COVID-19 conference in Indonesia (Setiawan et al., 2021).

\section{Theoretical review}

\subsection{Critical Thinking}

The process of criticizing an idea involves conducting an objective investigation, taking into account a variety of facts and viewpoints, and deriving fair and logical conclusions from the results of that study (Coviello, 2015). In order to improve our performance, critical thinking is the process of analyzing and reviewing the outcomes of our cognitive processes and thoughts on how we may make great choices or solve issues in an acceptable manner, among other things (Amankwah-Amoah et al., 2021). This task involves a variety of activities including the conceptualization and application of knowledge; the analysis, synthesis, and evaluation of information acquired via observation and experience; reflection, reasoning, and communication (Adam \& Alarifi, 2021; Prasanna et al., 2019). According to this idea, business managers need critical thinking abilities in order to grow their organizations, particularly in the face of challenges such as the present COVID-19 epidemic (AmankwahAmoah et al., 2021; Rakshit et al., 2021). Critical thinking is an indispensable ability for achieving success in both daily life and the workplace (Desouza \& Awazu, 2006; Ramli et al., 2019). Those who are able to think critically will have more opportunities in their professional, academic, and everyday life than those who are unable to think critically (Rabie et al., 2016). It is a way of thinking that can be applied to any subject, material, or problem and in which the thinker improves the quality of his or her reasoning by regulating and enforcing intellectual standards on the structures inherent in cognition 
(Kumar \& Kalse, 2021). It is a way of thinking that can be applied to any subject, material, or problem. Others feel that critical thinking is a necessary ability for people who deal with issues on a daily basis, such as corporate managers, and that critical thinking should be taught in schools (Prasetyo \& Kistanti, 2020). To be effective in their positions, business managers must be able to think critically in order to be creative in their approaches (Sinha \& Verma, 2020). In light of the above empirical perspectives, critical thinking abilities are defined as the capacity of a person to think more profoundly via the study and evaluation of facts (Amankwah-Amoah et al., 2021; Ramli et al., 2019). In order to collect information, a variety of techniques may be utilized, including personal experience, observation, and paying attention to the conduct of others, among others (Paik et al., 2017). According to the researches of Amankwah-Amoah (Amankwah-Amoah et al., 2021), Prasetyo \& Kristanti (Prasetyo \& Kistanti, 2020) and also Rakshit et al. (Rakshit et al., 2021), any one who is proficient in critical thinking will be able to make sound choices or take appropriate action when faced with a difficult situation. This capability is particularly essential in circumstances such as the COVID-19 pandemic, in which companies are forced to shut as a consequence of government lockdown measures, resulting in a reduction in the number of workers and a reduction in the buying power of the general public (Amankwah-Amoah et al., 2021; Rakshit et al., 2021). It is necessary to have a serious plan for dealing with these issues in this scenario. Therefore, this research proposes the following hypothesis:

\section{Hypothesis 1: Critical thinking influences on MSME's performance.}

\subsection{Creativity}

The ability of an employee to think critically as well as creatively is essential to the company's success (Desouza \& Awazu, 2006). Profit maximization can only be achieved through encouraging employees' use of their creativity and fostering innovation (Amankwah-Amoah et al., 2021). As a result, workers must be allowed to use their talents as they see appropriate so that the business may profit from their efforts (Desouza \& Awazu, 2006; Mujanah et al., 2017; Viswanathan \& Telukdarie, 2021). It's critical for a company's expansion since creativity is the ability to generate new ideas and uncover new perspectives on problems and opportunities. As a result, creativity or creative thinking ability is an activity that helps solve issues by utilizing unconscious experience processes, such as fluency in producing numerous ideas, flexibility in using time to create different answers, and uniqueness in the generated ideas or solutions (Fong et al., 2018; Ramli et al., 2019). The ability to contribute value, create value, and identify business possibilities is closely linked to the ability to think creatively (Cao \& Ali, 2018). An entrepreneurial scenario in the future must be shown using innovative thinking patterns to give a picture that can't be generated just by studying present trends (Desouza \& Awazu, 2006; Ramli et al., 2019). As a consequence, creativity is essential when it comes to coming up with new ideas and coming up with new approaches to challenges and opportunities as a company develops (Kumar \& Kalse, 2021). As a company grows, creativity becomes more essential because it has the ability to bring new ideas to bear in challenging situations (Crovini et al., 2021; Melnyk et al., 2021; Rakshit et al., 2021). Business intelligences will be able to create something new that attracts prospective customers as soon as they are capable of thinking beyond what is already accessible (Ahokangas et al., 2021; Andronikidis et al., 2021; Scuotto et al., 2021). As the capacity to create something new and suitable for a specific situation, both innovation and creativity are defined, they play an essential role in the creation of new companies as well as the survival of current ones operating on a worldwide level (Bodlaj \& Čater, 2022; Canhoto et al., 2021; Cerchione et al., 2016). Studies show that employee creativity has a favorable and substantial impact on both organizational innovation and overall business success (Crovini et al., 2021; Prasanna et al., 2019; Rakshit et al., 2021). Due to the perspective of Bouwman et al. (2019), Prasanna et al. (Prasanna et al., 2019) and also Weaven et al. (2021), innovative people can create new products and services, which is why it's critical for companies to be innovative if they want to stay competitive at times like the present COVID-19 pandemic. Therefore, this research proposes the following hypothesis:

\section{Hypothesis 2: Creativity significantly influences on MSME's performance.}

\subsection{MSMEs' Performance}

Capacity to achieve one's goals is a measure of a profitable enterprise (Amankwah-Amoah et al., 2021; Kekezi, 2021; Tao et al., 2019). The competitiveness may be attributed to a variety of organizational abilities, particularly experience, creativity, and the appropriate use of technology (Mujanah et al., 2017; Tao et al., 2019). The performance of a business is critical to its long-term viability and success (Prasanna et al., 2019). It is necessary for entrepreneurs to be able to think critically and creatively in order to successfully develop their businesses (Bouwman et al., 2019; Viswanathan \& Telukdarie, 2021). For businesses that emphasize uniqueness and need continuous innovation to stay up with changing customer tastes, this is especially true. Whenever a company achieves its quality and quantity objectives within a certain time period, it is considered to be doing well (Fianto, 2018; Ramli et al., 2019). The ultimate result of a process may be used to determine the success of the operation (Kumar \& Kalse, 2021). According to behavioral performance management, an individual's performance is measured by the quantity and also quality of services that they provide to customers (Paik et al., 2017; Prasanna et al., 2019). When it comes to assessing performance, the measurement design must be extremely clear. Performance measurement is a set of measures that may be used to evaluate present and future performance, regardless of whether a business is profitoriented or not (Desouza \& Awazu, 2006; Paik et al., 2017; Rabie et al., 2016). The total performance of a business is measured by the outcomes it has accomplished as well as the methods it has used to fulfil the necessary job or project (Paik 
et al., 2017). MSMEs may use past investment success to forecast future growth, as well as a rise in corporate profits to demonstrate that consumers are satisfied with the company's goods and services, to make predictions (Colovic, 2021; Pu et al., 2021). Companies that have been sold to the public on stock exchanges must maintain a continuous increase in earnings in order to retain their appeal to potential investors ( $\mathrm{Pu}$ et al., 2021). Assets, profitability, and labor productivity are all measures that may be used to determine how profitable a business is growing (Colovic, 2021). The majority of MSMEs in Indonesia assess both their financial and non-financial performance (Adam \& Alarifi, 2021). Product quality and customer satisfaction ratings are used to assess the former, while profit margins and cash-flow situations are used to assess the latter (Canhoto et al., 2021; Coyte et al., 2012).

A major negative impact of COVID-19 has been seen by Indonesia's MSMEs, particularly by the decreasing performance of MSMEs. As a result of the growth of COVID-19, consumption and buying power have both decreased, which has also had an effect on supply and trade as well (Adam \& Alarifi, 2021; Amankwah-Amoah et al., 2021; Rakshit et al., 2021). The probability of layoffs is high, which will result in increased unemployment and a reduction in the buying power of consumers. As a result, this scenario intensifies the difficulties already experienced by all parties concerned. Due to this, based on the views of Bouwman et al. (Bouwman et al., 2019), Prasanna et al. (Prasanna et al., 2019) and also Weaven et al. (Weaven et al., 2021), it is likely that sales of Indonesian MSMEs would suffer as a consequence of the situation. MSMEs owners and managers must thus be able to think critically and creatively about how to grow their companies within the present COVID19 period (Adam \& Alarifi, 2021; Amankwah-Amoah et al., 2021).

\section{Research methodology}

A quantitative technique is used in this study, as well as an explanatory research method, which explains the connection between variables. A questionnaire instrument packaged for validity and reliability was used to gather data via a survey technique. These responses were classified using a 5-point Likert scale, a research scale intended to assess respondents' attitudes and views by selecting answers that correlate to their opinions. The main data source utilized was Google Forms with shared links. Each question is given a score ranging from 1 to 5, with 1 representing strong agreement and 5 representing extreme disagreement, or from always to never. Before it was distributed, the questionnaire had validity and reliability verified.

\subsection{Population and Sample}

Participants in the research were the owners or managers in a variety of Indonesian MSMEs, including those in Surabaya, Yogyakarta, and Bandung, among other cities. The participants come from a wide range of different social backgrounds. In the culinary, fashion, food, and souvenirs industries, sampling was done on purpose in 108 small businesses with a workforce of more than five employees in the culinary, fashion, food, and souvenirs sectors, and samples were gathered at random from these businesses using Google Forms. On average, sampling with an unlimited population yields at least four or five times the number of indicators examined, according to current estimates (Malhotra et al., 2017). Consequently, four to five times as many samples were gathered for this research than were originally planned. It is estimated that 80 MSMEs multiplied by five equal a total of 80 MSMEs will participate in this research, which will include 16 indicators. Therefore, if this research uses more than the necessary basic minimum of 108 samples, it will go above and above the minimum requirement.

\subsection{Data Collection and Analysis}

Data were gathered and processed using the SmartPLS program, which is based on variance and uses Partial Least Squares (PLS) to arrive at the conclusions (Hair \& Sarstedt, 2021). Hypotheses were tested once the data had been collected and processed (Hair et al., 2018). In PLS regression analysis, as can be seen from the interaction between the moderating variable and the predicting factors, the moderating variable maintains its place in the PLS analysis in the same way as it did in the regression analysis (Shiau et al., 2019). Moderation factors are independent variables that have the ability to enhance or decrease the effect of other latent variables on one another, depending on their position in the model. Depending on its nature, the moderating variable may be either positive or negative.

\subsection{Variable Measurement}

MSMEs' ability to think critically, to be creative, and to perform well are all characteristics evaluated in this study, and they are all included among the variables studied. Facione (2015) defines critical thinking as the ability to judge something, which results in the processes of interpretation, analysis, evaluation, and inference. It also includes the ability to explain something by relying on evidence, concepts, criteria, or contextual considerations that can be used as a basis for decision-making, among other things. A critical thinking talent may also be defined as the ability to analyze anything, which leads to the processes of identification and analysis before being assessed and inferred from the data collected and analyzed. Critical thinking in this research is divided into seven indicators: (1) truth seeking, (2) open-minded, (3) analyticity, (4) systematicity, (5) selfconfidence, (6) inquisitiveness, and (7) maturity of judgment. Creativity, in this study, is based on the theory of Torrance (1974) which stated creativity as the ability to find new relationships or relatedness to see the subject from a new perspective 
and form a new combination of two or more concepts. Creative thinking is characterized according to Pesout and Netfield (2021) and Yoon (2017) who used Torrance (1974) principles as follows: (1) fluency, (2) flexibility, (3) originality, (4) problem sensitivity, and (5) elaboration.

For the objectives of this study, the literature was reviewed to determine the performance of MSMEs. A variety of factors are considered in evaluating MSMEs in Indonesia, including financial and nonfinancial factors. Financial success is assessed by looking at things like company profit, cash flow situation, and budget, among other things. Non-financial performance is measured by looking at things like product quality and customer satisfaction, among other things.

\subsection{Research Participants}

The managers of MSMEs in Indonesia were among those who answered the survey's questions. It is essential to understand the profile of respondents in this research in terms of gender, kind of business, and length of time in the company before presenting the findings of the analysis in this study. The respondents of this research were 108 MSMEs from Indonesia's East Java, Central Java, West Java, and Bali provinces, with the majority being from East Java. Males made up 53.70 percent of the answers, while females made up 46.30 percent, indicating that men were more prevalent in this region. Food and beverage businesses (restaurants, cafes, and cracker production; 35.18 percent), apparel and fashion (23.15 percent), Batik souvenirs (19.44 percent), and others, such as event planning, beauty care, design and photography (photo studio), and other businesses (photography and photo studio) account for the majority of respondents (22.22 percent). In other words, the companies operated by the respondents to this survey range from manufacturing to providing services. The majority of MSMEs have been in operation for 5-10 years (64.82 percent), with the remainder having been in operation for more than 10 years (15.74 percent); others have been in operation for between 2 and 4 years (19.44 percent). That the respondents in this research are mature enough and have sufficient experience in operating their companies is shown by their responses.

\section{Results}

\subsection{Testing the Hypothesis}

The hypothesis in this research was tested using the SmartPLS software and structural equation modeling, which were both utilized in this investigation. In the model, both external models (model measurements) and internal models (model computations) are incorporated (structural models). Before any of the models in this research can be assessed, it is necessary to evaluate the outer and inner models first. The validity of an indicator is determined by its loading factor, which must be higher than 0.5 for the build for which it is designed (Hair et al., 2018; Hair \& Sarstedt, 2021; Shiau et al., 2019). It was determined in this research that critical thinking has a loading factor ranging from 0.708 to 0.849 based on the indicator's item questions, with each significant likelihood of being $(p) 0.001$ because of the outer loading analysis. It follows therefore that the question item for each indicator is legitimate, and as a result of this, the critical thinking variable for each indicator is valid as well.

\subsection{Outer Model Evaluation}

In accordance with the reflective indicators, validity testing was carried out to determine whether or not there was a relationship between the item and the construct scores. The use of reflecting indicators is necessary in this study since it is concerned with assessing perceptions. In comparison to the desired construct, a valid indication is one that has a loading factor higher than 0.5 (Hair et al., 2018). According to the findings of the research, all variables have a loading factor that is more than 0.5 , which is the recommended amount. The lowest loading factor value is 0.853 , which corresponds to the Creativity indicator, and the smallest variable loading factor value is 0.83 , which corresponds to the creativity variable, and the lowest variable loading factor value is 0.83 , which corresponds to the creativity variable, respectively. That the indicators used in this study are valid or that they have met the requirements for convergent validity, respectively, is shown by the results. In order to determine discriminant validity, the square root of the average variance extracted (AVE) value must be taken into consideration. The recommended value is one that is more than or equal to 0.5 (Hair et al., 2018). A value higher than 0.5 is obtained for the AVE value for all variables as a result of the calculations performed (Shiau et al., 2019). When a validity test standard has a square root value higher than 0.5 , it satisfies the requirements of a genuine validity test standard; thus, it is valid (Hair \& Sarstedt, 2021). The reliability of indicators of latent variables is also used to assess whether or not they are reliable; this may be seen from the composite reliability value of indicators that measure construct variables, which is a kind of reliability value. In this test, values higher than 0.7 are considered to be acceptably close to the mean (Hair \& Sarstedt, 2021). Consequently, the composite reliability analysis produced values greater than 0.7 for all constructs; as a result, all constructs in the estimated model meet the reliable criteria (Hair et al., 2018). According to the results of Cronbach's alpha analysis, which reveals values ranging between 0.91 and 0.96 for all four variables in this study, all four variables in this study are reliable. When the SmartPLS output provides results with a value higher than 0.9 and when all constructs have values greater than 0.6 , the reliability test may be strengthened even further by adding Cronbach's alpha as a measure of consistency. A value of 0.802 is the lowest that can be achieved. Aside from that, the SmartPLS software was used in this research for the purpose of doing communality tests. According to the findings, the value of communality in each construct 
for creativity was 0.78 , the value of communality in each construct for critical thinking was 0.784 , and the value of communality in each construct for performance was 0.835 , with the value of communality in each construct for critical thinking being 0.78 . Consequently, the results of the tests utilizing Composite Reliability and Cronbach's Alpha show that each variable has a value higher than 0.05 , demonstrating that the data is reliable in nature.

\subsection{Inner Model}

Following the completion of the requirements for the outer model, the structural model (inner model) was put to the test. As a result of the R-Square value in the construct, the MSMEs' performance construct has an R-Square value of 0.319, which indicates that the role of critical thinking and creativity impacted the performance of MSMEs by 31.9 percent. As shown in the t-statistic value, critical thinking and creativity have a partial impact on the performance of MSMEs when the t-statistic is less than 1.96; as a result, there is an effect of exogenous variables on endogenous variables or an effect of endogenous variables on exogenous variables in the model. Alternatively, if the t-statistic is less than 1.96, it indicates that there is no impact of exogenous factors on endogenous variables, or no effect of endogenous variables on exogenous variables, respectively. The results of the t-statistical calculations obtained via the assessment of the inner model are shown in Fig. 1.

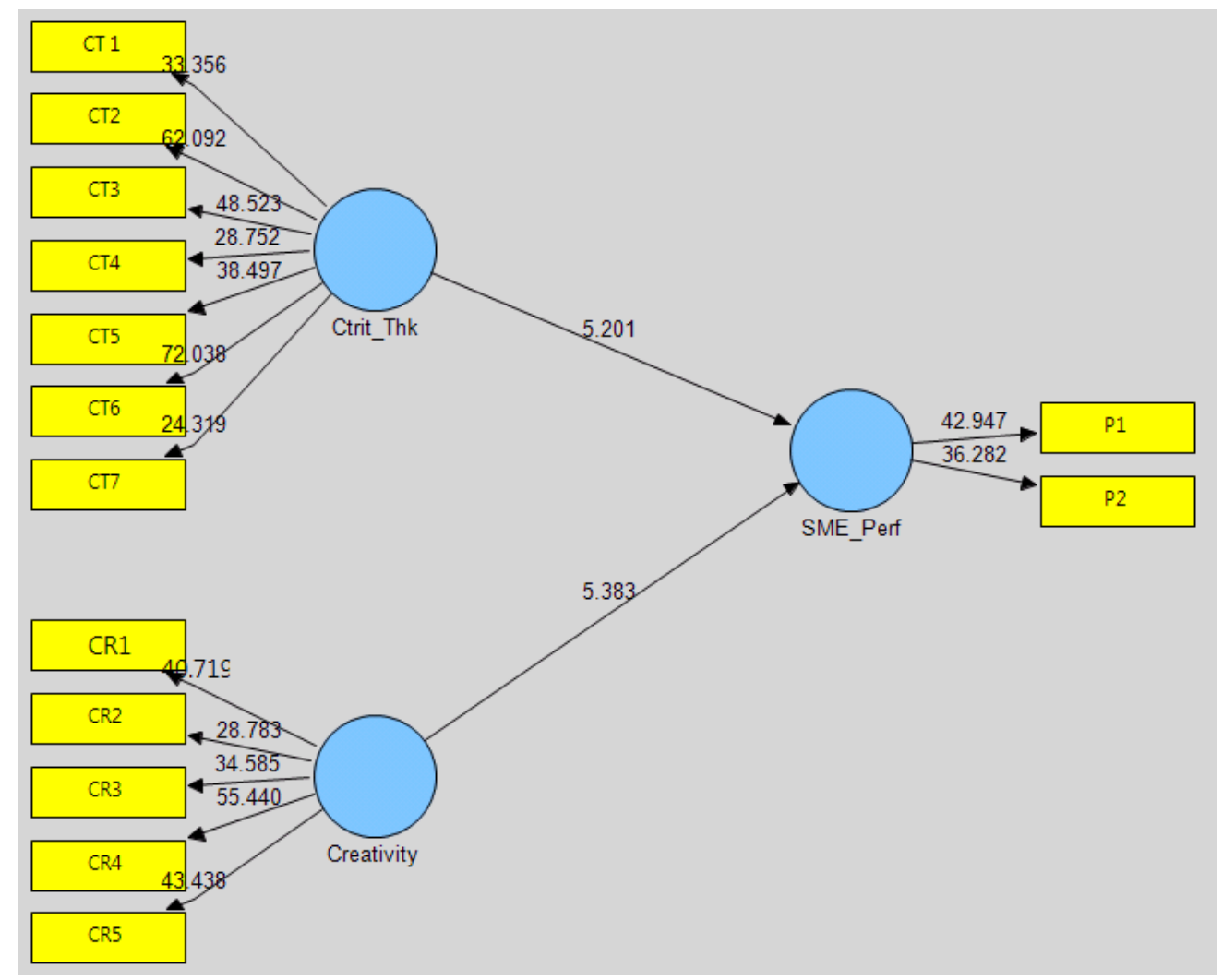

Fig. 1. Inner Model Algorithm

Based on the results of the calculation of the path coefficient test produced by the SmartPLS software above, the influence between the hypothesized variables in this study can be described as follows (Table 1):

Table 1

Hypothesis Test

\begin{tabular}{lcccc}
\hline & $\begin{array}{c}\text { Original } \\
\text { Sample (O) }\end{array}$ & $\begin{array}{c}\text { Sample } \\
\text { Mean (M) }\end{array}$ & $\begin{array}{c}\text { Standard Error } \\
\text { (STERR) }\end{array}$ & $\begin{array}{c}\text { T Statistics } \\
(|\mathbf{O} / \mathbf{S T E R R}|)\end{array}$ \\
\hline Ctrit_Thk $\rightarrow$ SME_Perf & 0,340 & 0,347 & 0,065 & 5,201 \\
Creativity $\rightarrow$ SME_Perf & 0,378 & 0,379 & 0,070 & 5,383 \\
\hline
\end{tabular}

Ability to think critically has a major impact on overall success in a company, and this is especially true in the financial sector. SmartPLS calculations have shown that critical thinking has a beneficial influence on the performance of a company, with a coefficient of 0.340 suggesting a favorable impact on performance. As shown by the t-statistic value of 5.201 ( $>1.96)$, 
this impact is statistically significant, suggesting that increases in critical thinking will result in substantial gains in business performance as well as overall performance. In businesses, the ability to think in a novel way has a major impact on the success of the enterprise. Creative thinking has a favorable impact on the overall success of a company's operations, according to the findings of the SmartPLS calculation. In COVID-19, according to the data, increases in creativity will lead to substantial gains in company performance as a consequence of increased innovation. This indicates that improvements in creativity will result in significant increases in business performance during COVID-19, as shown by the t-statistic of 0.378 (which is more than 1.96).

\section{Discussions}

This research examines the effect of critical thinking on MSME business performance and creative thinking on MSME business performance and finds that the two independent variables in this research have a significant influence on MSME business performance. An explanation of the reasons for these findings is presented in the following parts. Self-confidence (which got the highest average score, 4.12), maturity (4.08), systematicity (which received the best average score), truth seeking, and analytic reasoning were the six measures of critical thinking employed in this research. As a result of the results, it was determined that business managers will need critical thinking skills during the COVID-19 pandemic, with selfconfidence being the most important critical thinking talent to develop, followed by maturity. As a result, in the current climate of the COVID-19 epidemic, MSMEs' managers must continually think maturely and be confident in their capacity to make incremental improvements to their organizations. MSMEs will benefit from critical thinking because it will enable them to successfully address issues by collecting information and logistics, developing effective ideas, and being able to engage different points of view as well as all current members, among other things. This shows that MSMEs can use critical thinking to find solutions to the many problems they will face in the future. It will help MSMEs manage time and money better, and it will give MSMEs the capacity to make breakthroughs in the promotion of their products and the production of income. As shown by the results of this study, critical thinking has a statistically significant effect on the performance of MSMEs operating in Indonesia. As a consequence, the results of this research corroborate the findings of Amankwah-Amoah (Amankwah-Amoah et al., 2021), Prasetyo and Kristanti (2020) and also Rakshit et al. (2021), which indicate that having ability to think critically may aid in the assessment and examination of issues which might emerge, as well as the discovery and analysis of alternative solutions to help the business survive in any scenario. The reason for this is because through practicing critical thinking, a manager or business owner will learn how to create ways to keep the company operating smoothly even when the usual amount of work is not put in. Someone who has excellent critical thinking abilities will also be able to engage in activities that need introspective and independent thinking. Someone who thinks critically will make use of their analytical and deductive thinking abilities. The learning experience will be more active than passively receiving information since someone who is capable of critical thinking will convey more ideas and assumptions than someone who just accepts what is said. Critical thinkers are always on the lookout for new ideas, arguments, and wide points of view. They are open to finding anything in a systematic manner. They will also be responsible for identifying, evaluating, and resolving problems. The ability to maximize rational thought has helped many entrepreneurs and business managers operate their companies more effectively, among other things, by recognizing possibilities to acquire commercial prospects in any circumstances or scenarios. In the process of analyzing information and ideas and assessing them, they are also vigilant in taking suitable and timely actions. According to this discovery, MSMEs can respond quickly to consumer needs in the case of a pandemic, such as the COVID-19 pandemic, if they are prepared. Research conducted to support this conclusion discovered that one method for MSMEs to survive the COVID-19 pandemic is to change the kind of products they sell. To prepare for the pandemic scenario, 52 percent of MSMEs in Indonesia have changed their business to selling frozen food (33.1 percent) and various types of cakes (17.1 percent) as part of their adaptation strategy, according to the results (Mudassir, 2020). A further result of this study was the discovery of an association between creativity and the performance of MSMEs in Indonesia that is both positive and statistically significant. It is supported by the findings of Bouwman et al. (2019), Prasanna et al. (2019) and also Weaven et al. (2021) who discovered that a person's ability to give birth to something new, in the form of ideas and real work, both as new works and in combination with things that already exist, has the potential to improve business performance, particularly in the face of a COVID-19 pandemic crisis with Work from Home (WfH) policies, social distance, and panic conditions, so that it has an impact on sales. The implementation of the COVID-19 has resulted in changes in business patterns, many of which are new. For example, the shift in people's buying habits from offline to online platforms because of the law's adoption has occurred. To survive and develop, MSMEs must adapt to these changes in patterns to be prepared to cope with the new normal conditions. Businesses of all sizes, including MSMEs, must take certain measures to survive in the new normal era. Adaptability requires the ability to innovate and be innovative to succeed. Entrepreneurs that utilize their creativity and agility in their thinking have the potential to create new and profitable business opportunities in their respective fields. Consider the importance of innovation in sales channels, ranging from offline synergy to online adaptability, as well as digital adaptability. Aside from product creation, entrepreneurs may also innovate on a larger scale. This is shown by the results of interviews and surveys, in which about 76 percent of respondents said that their businesses had closed because of a lack of customer service. But they do recognize that their businesses continue to exist and that they continue to generate revenue because of their ability to create new ideas and take advantage of opportunities (64.60 percent). They have totally stopped their companies since operating a company is difficult owing to the lockdown, WfH circumstances, and social distance that has resulted from the situation. This is particularly true in the industries of business travel, transportation, apparel, and consulting. Still, they are trying to diversify their operations into other areas, such as the 
sale of food and other necessities for consumers such as masks, hand sanitizer, and other necessities for consumers. Food, restaurant, and fashion industry professionals on the other hand continue to conduct their activities online; in addition, about 43 percent of them rely on shipping, courier, and other shipping services to make their operations more efficient and effective. Similarly to what Bouwman et al. (2019), Prasanna et al. (2019), Weaven et al. (2021), Herman (2020), Amankwah-Amoah (2021), Prasetyo \& Kristanti (2020) and also Rakshit et al. (2021) said, MSMEs owners and managers must be analytical and innovative in order to be responsive to shifts in customer behavior. A digitization strategy that may help companies in changing at the required pace is needed. Long-term survival is dependent on the ability to adapt to a new normal as soon as it becomes the new normal. Several businesses, especially those engaged in the digital or online sector, are seeing rapid growth. Many people choose to stay at home because they have the option of working from home and because of the existence of social distance. As a result, technology is very essential in this situation. The accomplishment of online business can be accomplished using marketplaces or e-commerce, which is becoming more accessible in the digital world, or establish an online shop through the use of a personal website, with the use of social media being highly recommended as a complement.

\section{Conclusion}

A study of the performance of Indonesian MSMEs during the COVID-19 epidemic is being carried out to determine how critical thinking and creativity influence the performance of small and medium-sized enterprises. 108 randomly chosen company managers participated in this research, which collected data via the use of a questionnaire instrument to gather information. The questionnaire instrument was administered via the use of online survey forms, which were used throughout the course of the study. After the information had been gathered, it was submitted to an investigation to see what information it could contain or reveal. In Indonesian MSMEs, critical thinking and innovation, according to the results, have a significant effect on their performance and are linked with higher levels of profitability. Continuous innovation is needed to maintain high levels of competitiveness while staying abreast of the most up-to-date technologies that are most suited to the needs of consumers. High-quality products and services are sought after by customers, and entrepreneurs and business owners who want to offer them must make an investment in the development of critical thinking and creative skills. To accomplish this job, a tremendous amount of time and money will be needed. It is anticipated that their initiatives will have positive consequences for a broad range of businesses, including their own. MSMEs stand to gain the most from the use of technology to assist them in staying in business. The use of technology to help companies of all kinds, but particularly MSMEs, stands to benefit the most from the use of technology to assist them in staying in business. The use of information technology by businesses of all kinds, especially MSMEs, has the potential to benefit them by expanding the market for their goods and services. Additionally, to improve the probability of the company's success, it is critical to evaluate and analyze the competence, conduct, and intellect of the company's founders and executives. When faced with the COVID-19 pandemic, MSMEs will need to be able to think critically and creatively in order to enhance their operational performance and ensure their long-term survival.

\section{Limitations and Future Research Recommendation}

This study yielded important findings regarding the performance of MSMEs in difficult times as a result of the COVID-19 pandemic. But on the other hand, this study has various limitations that can be improved in future research. In an effort to find answers to the performance problems of MSMEs during the COVID-19 pandemic, this study examines two variables that determine the performance of MSMEs, namely critical thinking and creativity. On the other hand, there are actually many other variables that can also determine the performance of MSMEs, but this research is limited to only examining critical thinking and creativity. Therefore, it is recommended for future research in order to examine other variables so as to reveal new facts on the performance of MSMEs. In the aspect of the research sample, this study also has limitations due to the small number of samples. Thus, future research can increase the number of samples and the diversity of sample characteristics so that the generalizability of the results of future research can be better. This study also did not examine aspects of organizational culture as a determining factor for improving the performance of MSMEs. Therefore, further measurement is needed in future research.

\section{References}

Adam, N. A., \& Alarifi, G. (2021). Innovation practices for survival of small and medium enterprises (SMEs) in the COVID19 times: the role of external support. Journal of Innovation and Entrepreneurship, 10(1). https://doi.org/10.1186/s13731021-00156-6

Ahokangas, P., Haapanen, L., Golgeci, I., Arslan, A., Khan, Z., \& Kontkanen, M. (2021). Knowledge sharing dynamics in international subcontracting arrangements: The case of Finnish high-tech SMEs. Journal of International Management. https://doi.org/10.1016/j.intman.2021.100888

Amankwah-Amoah, J., Khan, Z., \& Wood, G. (2021). COVID-19 and business failures: The paradoxes of experience, scale, and scope for theory and practice. European Management Journal, 39(2), 179-184. https://doi.org/10.1016/j.emj.2020.09.002

Andronikidis, A., Karolidis, D., \& Zafeiriou, G. (2021). Reflections on grounding firm innovation and viability. European Management Journal, 39(1), 2-8. https://doi.org/10.1016/j.emj.2020.11.003 
Bodlaj, M., \& Čater, B. (2022). Responsive and proactive market orientation in relation to SMEs' export venture performance: The mediating role of marketing capabilities. Journal of Business Research, 138, 256-265. https://doi.org/10.1016/j.jbusres.2021.09.034

Bouwman, H., Nikou, S., \& de Reuver, M. (2019). Digitalization, business models, and SMEs: How do business model innovation practices improve performance of digitalizing SMEs? Telecommunications Policy, 43(9). https://doi.org/10.1016/j.telpol.2019.101828

Canhoto, A. I., Quinton, S., Pera, R., Molinillo, S., \& Simkin, L. (2021). Digital strategy aligning in SMEs: A dynamic capabilities perspective. Journal of Strategic Information Systems, 30(3). https://doi.org/10.1016/j.jsis.2021.101682

Cao, X., \& Ali, A. (2018). Enhancing team creative performance through social media and transactive memory system. International Journal of Information Management, 39, 69-79. https://doi.org/10.1016/j.ijinfomgt.2017.11.009

Cerchione, R., Esposito, E., \& Spadaro, M. R. (2016). A literature review on knowledge management in SMEs. Knowledge Management Research and Practice, 14(2), 169-177. https://doi.org/10.1057/kmrp.2015.12

Colovic, A. (2021). Leadership and business model innovation in late internationalizing SMEs. Long Range Planning, 102083. https://doi.org/10.1016/j.lrp.2021.102083

Coviello, N. (2015). Re-thinking research on born globals. Journal of International Business Studies, 46(1), 17-26. https://doi.org/10.1057/jibs.2014.59

Coyte, R., Ricceri, F., \& Guthrie, J. (2012). The management of knowledge resources in SMEs: An Australian case study. Journal of Knowledge Management, 16(5), 789-807. https://doi.org/10.1108/13673271211262817

Crovini, C., Ossola, G., \& Britzelmaier, B. (2021). How to reconsider risk management in SMEs? An Advanced, Reasoned and Organised Literature Review. European Management Journal, 39(1), 118-134. https://doi.org/10.1016/j.emj.2020.11.002

Desouza, K. C., \& Awazu, Y. (2006). Knowledge management at SMEs: Five peculiarities. Journal of Knowledge Management, 10(1), 32-43. https://doi.org/10.1108/13673270610650085

Facione, P. A. (2015). Critical thinking: What it is and why it counts. Insight Assessment, 1(30).

Fianto, A. Y. A. (2018). Antecedents of customer satisfaction for small medium entreprises product in Indonesia. International Journal of Civil Engineering and Technology, 9(11).

Fong, P. S. W., Men, C., Luo, J., \& Jia, R. (2018). Knowledge hiding and team creativity: the contingent role of task interdependence. Management Decision, 56(2), 329-343. https://doi.org/10.1108/MD-11-2016-0778

Hair, J. F., Black, W. C., Babin, B. J., \& Anderson, R. E. (2018). Multivariate Data Analysis (8th Editio). Cengage.

Hair, J. F., \& Sarstedt, M. (2021). Explanation Plus Prediction — The Logical Focus of Project Management Research. Project Management Journal, 52(4), 319-322. https://doi.org/10.1177/8756972821999945

Kekezi, O. (2021). Diversity of experience and labor productivity in creative industries. Journal for Labour Market Research, 55(1). https://doi.org/10.1186/s12651-021-00302-3

Kumar, A., \& Kalse, A. (2021). Usage and adoption of artificial intelligence in SMEs. Materials Today: Proceedings. https://doi.org/10.1016/j.matpr.2021.01.595

Malhotra, N. K., Nunan, D., \& Birks, D. F. (2017). Marketing Research-An Applied Approach (6th Editio). Pearson Education Limited.

Melnyk, S. A., Schoenherr, T., Verter, V., Evans, C., \& Shanley, C. (2021). The pandemic and SME supply chains: Learning from early experiences of SME suppliers in the U.S. defense industry. Journal of Purchasing and Supply Management, 27(4). https://doi.org/10.1016/j.pursup.2021.100714

Mujanah, S., Ratnawati, T., \& Kusmaningtyas, A. (2017). The effect of competence, emotional quotient , and financial quotient on the business performance of small and medium enterprises in Surabaya, Indonesia. Proceedings of the 16th International Symposium on Management (INSYMA 2019), August 1945.

Paik, J. H., Kim, M. K., \& Park, J. H. (2017). The antecedents and consequences of technology standardizations in Korean IT small and medium-sized enterprises. Information Technology and Management, 18(4), 293-304. https://doi.org/10.1007/s10799-016-0268-2

Pesout, O., \& Nietfeld, J. L. (2021). How creative am I?: Examining judgments and predictors of creative performance. Thinking Skills and Creativity, 40, 100836. https://doi.org/10.1016/J.TSC.2021.100836

Prasanna, R. P. I. R., Jayasundara, J. M. S. B., Gamage, S. K. N., Ekanayake, E. M. S., Rajapakshe, P. S. K., \& Abeyrathne, G. A. K. N. J. (2019). Sustainability of SMEs in the competition: A systemic review on technological challenges and SME performance. Journal of Open Innovation: Technology, Market, and Complexity, 5(4). https://doi.org/10.3390/joitmc5040100

Prasetyo, P. E., \& Kistanti, N. R. (2020). Human capital, institutional economics and entrepreneurship as a driver for quality \& sustainable economic growth. Entrepreneurship and Sustainability Issues, 7(4), 2575-2589. https://doi.org/10.9770/jesi.2020.7.4(1)

Pu, G., Qamruzzaman, M., Mehta, A. M., Naqvi, F. N., \& Karim, S. (2021). Innovative Finance, Technological Adaptation and SMEs Sustainability: The Mediating Role of Government Support during COVID-19 Pandemic. Sustainability, 13(16), 9218. https://doi.org/10.3390/su13169218

Rabie, C., Cant, M. C., \& Wiid, J. A. (2016). Training and development in SMEs: South Africa's key to survival and success? Journal of Applied Business Research, 32(4), 1009-1024. https://doi.org/10.19030/jabr.v32i4.9717

Rakshit, S., Mondal, S., Islam, N., Jasimuddin, S., \& Zhang, Z. (2021). Social media and the new product development during COVID-19: An integrated model for SMEs. Technological Forecasting and Social Change, 170. 
https://doi.org/10.1016/j.techfore.2021.120869

Ramli, Y., Firdaus, I., Arief, H., \& Setiawan, M. (2019). Mobile Marketplace As a Medium for Selling Micro Small Medium Enterprise Products. ICCD, 2(1), 55-59. https://doi.org/10.33068/iccd.vol2.iss1.209

Scuotto, V., Nicotra, M., Del Giudice, M., Krueger, N., \& Gregori, G. L. (2021). A microfoundational perspective on SMEs' growth in the digital transformation era. Journal of Business Research, 129, 382-392. https://doi.org/10.1016/j.jbusres.2021.01.045

Setiawan, Arif, D., Mahmudah, S., Agustina, H., \& Martah, V. (2021). The effect of supply chain management on multichannel retailing and business performance. Uncertain Supply Chain Management, 9(4), 823-830. https://doi.org/10.5267/j.uscm.2021.8.007

Shiau, W.-L., Sarstedt, M., \& Hair, J. F. (2019). Internet Research Using Partial Least Squares Structural Equation Modeling (PLS-SEM). Internet Research, 29(3), 398-406. https://doi.org/https://doi.org/10.1108/IntR-10-2018-0447

Sinha, S. K., \& Verma, P. (2020). Impact of Sales Promotion's Benefits on Perceived Value: Does Product Category Moderate the Results? Journal of Retailing and Consumer Services, 52(July 2019 ), 101887. https://doi.org/10.1016/j.jretconser.2019.101887

Tao, J., Ho, C. Y., Luo, S., \& Sheng, Y. (2019). Agglomeration economies in creative industries. Regional Science and Urban Economics, 77, 141-154. https://doi.org/10.1016/j.regsciurbeco.2019.04.002

Tiago, F., Gil, A., Stemberger, S., \& Borges-Tiago, T. (2020). Digital sustainability communication in tourism. Journal of Innovation and Knowledge. https://doi.org/10.1016/j.jik.2019.12.002

Torrance, E. P. (1974). Norms-Technical Manual: Torrance Tests of Creative Thinking. Ginn and Co.

Viswanathan, R., \& Telukdarie, A. (2021). A systems dynamics approach to SME digitalization. Procedia Computer Science, 180, 816-824. https://doi.org/10.1016/j.procs.2021.01.331

Weaven, S., Quach, S., Thaichon, P., Frazer, L., Billot, K., \& Grace, D. (2021). Surviving an economic downturn: Dynamic capabilities of SMEs. Journal of Business Research, 128, 109-123. https://doi.org/10.1016/j.jbusres.2021.02.009

Yoon, C. H. (2017). A validation study of the Torrance Tests of Creative Thinking with a sample of Korean elementary school students. Thinking Skills and Creativity, 26, 38-50. https://doi.org/10.1016/J.TSC.2017.05.004

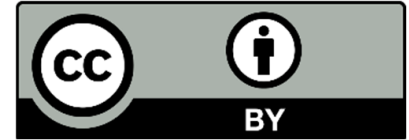

(C) 2022 by the authors; licensee Growing Science, Canada. This is an open access article distributed under the terms and conditions of the Creative Commons Attribution (CCBY) license (http://creativecommons.org/licenses/by/4.0/). 